\title{
Teknoloji Transfer Performansının Kalite Performansına Etkisi
}

\section{The Impact of Technology Transfer Performance on Quality Performance}

\author{
Gülin İdil SÖNMEZTÜRK BOLATAN', \\ Sıtkı GÖZLÜ²
}

0000-0002-9668-3584

0000-0002-8697-0651

\begin{abstract}
ÖZET
Artan rekabet ortamında firmalar, müşteri ihtiyaç ve beklentilerini en iyi şekilde karşılayabilmek için maliyet, kalite, hızlı teslim süresi gibi unsurlarda iyileşmeye çalışmaktadırlar. Bu iyileşmenin sağlanması hem donanımlarını yenilemeyi hem de iş süreçlerini yenilemeyi gerektirmektedir. $\mathrm{Bu}$ yeniliklerin sağlanması ise ancak teknolojik gelişim ile mümkün olmaktadır. Bu çalışmanın amacı, teknoloji transferinin kalite performansını etkileyip etkilemediğini, etkiliyor ise teknoloji transferinin kalite performansını pozitif veya negatif olarak hangi yönde etkilediğini araştırmaktır. Araştırma modelinin analizinde yapısal eşitlik modellemesi kullanılmıştır. Araştırma sonucunda teknoloji transferinin kalite performansına pozitif yönde bir etkisi olduğu ve teknoloji transfer performansının farklı kalite performans ölçütlerine etkisi arasında fark olmadığı sonuçları bulunmuştur.
\end{abstract}

Anahtar Kelimeler: Teknoloji transferi, teknoloji transfer performansı, kalite performansı

\section{GíRiş}

Teknoloji bir mal veya hizmetin üretimi için gerekli ve uygulanan bilgi, know-how ve deneyimlerdir. Malların ve hizmetlerin üretimlerinin planlanmasından dağıtılmasına kadar geçen süredeki tüm teknik ve yönetsel yöntemler ve bilgiler teknolojidir. Teknoloji; araçlar, makinalar, üretim yöntemleri, bir işin yapılması için gerekli bilgiler olabilir. Dolayısıyla teknoloji hem somut hem de soyut faktörleri içinde barındırmaktadır (Abdul vd., 2012). Teknoloji transferi ise en genel tanımı ile bir ülkedeki bilgi veya uzmanlığın başka ülkedeki insanlara iletilmesidir. Teknoloji transferi, teknolojinin bir organizasyondan diğerine geçmesi şeklinde de olabilmektedir. Betts ve Santoro

\begin{abstract}
Nowadays, there is tough competition in global markets so that companies must be able to meet their customers' expectations and needs satisfactorily. This is possible through technological development. This study's purpose is to determine whether technology transfer affects on the quality performance. If technology transfer affects on the quality performance, the way of effects is searched, is it affected by positively or negatively. Structural equation modeling was used for research model analysis. The results of research show that technology transfer affects quality performance positively and technology transfer performance does not have difference effects on the different quality performance criteria.
\end{abstract}

Keywords: Technology transfer, performance of technology transfer, quality performance. 
Teknoloji transferi türleri çok çeşitli olmakla birlikte en çok bilinen türleri şöyledir: teknoloji transfer sözleşmeleri (lisans anlaşmaları, yönetim sözleşmeleri, makine ithalatı, ekipman, ithalatı, teknik işbirliği, doğrudan yabancı yatırımlar, arge faaliyetleri, know-how anlaşmaları, danışmanlık hizmeti alımları, danışman ve yabancı uzman istihdamı, firmanın kendisince yürütülen ar-ge faaliyet ve projeleri, üniversite - sanayi işbirlikleri, anahtar teslimi tesis yatırımları, finansal kiralama, ticari ziyaretler, franchising, şirket satın almaları, bilimsel ve teknik personel değişimi, bilim ve teknoloji konferansları ve ticari tanıtımlar, fuarlara katılım, seminerler, ortak girişim (joint venture) anlaşmaları, uluslararası teknik programlar, eğitim alma ve öğrenim, açık literatür (dergiler, kitaplar, literatür, makaleler vb.).

Deming kaliteyi, müşterilerin intiyacına cevap verebilen, düşük maliyetli, güvenilir ve standart olabilmek olarak tanımlamaktadır. Kalite, müşterilerin ihtiyaçlarını veya ihtiyaçlarından fazlasını karşılamaktır (Corbett ve Rastrick, 2000). Kalite, amaçlara uygunluk derecesidir.

Teknolojik yenilik gerçekleştiren firmalar tüm firma süreçlerinde insan faktörünü azaltmakta; insan faktörünün yerini bilgisayarlar, makineler, bilgisayar programları gibi yeni teknolojiler almaktadır. Bu durum teknoloji transferini henüz gerçekleştirmemiş firmalarda bazı tedirginliklere sebep olmaktadır. Firmanın tüm faaliyet süreci boyunca kullandığı, alıştığı eski sistemi kullanmayı bırakmak ve daha önce hiç denemediği yeni bir sistemi transfer edip öğrenmek, kullanmak firmalarda kaygılara sebep olabilmektedir. Birçok firma yöneticisi yeni bir teknoloji transfer etmeden önce bu yeni teknolojinin firma süreçlerinde aksaklıklara sebep olabileceğini düşünmektedir. Dolayısıyla birçok firma, yeni bir teknolojinin transferinin firmanın kalite performansının düşmesine sebep olabileceğini düşünmekte ve yeni teknoloji transfer etmeyi bu kaygı sebebi ile istememektedir. Yeni teknolojiler birçok firma sürecinin işlem süresini kısaltmakta, insan faktörü kullanımını en aza indirmektedir. İşlemlerin kısa sürede gerçekleşmesi ve insan faktörünün geri planda kalması firmaları hata yapılması, çeşitli aksaklıkların olması ve dolayısıyla da kalitenin düşmesi yönünde kaygılandırmaktadır. Teknoloji transferinin kalite performansına etkisi ile ilgili yapılmış bir araştırma bulunmamaktadır. Bu sebeple de teknoloji transferinin kalite performansını mutlaka arttıracağı veya mutlaka azaltacağı yönünde bir ifade kullanmak yanlış olur.
Yeni teknolojilerin geliştirilmesi pahalı, karmaşık ve uzun süren bir süreçtir. Bu sebeple teknolojilerin geliştirilmesi yerine teknolojinin transfer edilmesi tercih edilmektedir. Transfer edilen yeni teknolojiler firmalara yenilik getirmektedir. Üretimde, süreçlerde, kullanılan bilgisayar programlarında, makinelerde yenilik oluşması firmaya birçok fayda sağlamaktadır. Çaış̧anların yaptıkları birçok işi çalışanlar yerine bilgisayarlar, makineler yapmakta ve böylece üretim süreleri kısalmakta, firmadaki maliyetler azalmakta, firma verimliliğini arttırabilmekte ve müşteri gereksinimlerine uygun yeni ürünler üretilebilmektedir. Ancak transfer edilen yeni teknolojilerin firmada oluşturduğu bu yenilikler firmanın kalite performansına nasıl etki edecektir? Teknolojik yeniliklerin firmadaki verimliliği çoğu zaman arttırdığı görülmektedir. Ancak verimlilik artışı her zaman kalite artışını da sağlamamaktadır. Literatür araştırması sonucunda teknoloji transfer performansının kalite performansına etkisini gösteren bir çalışmaya rastlanmamıştır ve bu eksikliğin giderilmesi amacıyla bir model geliştirilmiştir. Yapılan literatür araştırmasında teknoloji transferi konusunda yapılmış çalışmalar ve firmaların kalite performansı konusunda yapılmış çalışmalar olduğu görülmüştür. Ancak teknoloji transferinin firmaların kalite performansına etkisi konusunda yazıımış bir çalışma bulunmamaktadır. Bu sebeple araştırmanın amacı teknoloji transferinin kalite performansını ve kalite yönetim başarısını nasıl etkilediğinin bulunmasıdır.

Bu çalışmada teknoloji transferinin kalite performansını etkileyip etkilemediği, etkiliyor ise teknoloji transferinin kalite performansını pozitif veya negatif olarak hangi yönde etkilediği araştırılmıştır.

\section{LITERATÜR ÖZETI}

\subsection{Kalite performansı}

Literatür araştırması sonucunda bu çalışmada kullanılmak üzere 14 adet kalite performans ölçütü belirlenmiştir. Ahire vd. (1996)'nin yaptığı çalışmada kalite ölçütleri; güvenilirlik, performans, dayanıklılık ve spesifikasyonlara (standartlara) uygunluk olarak bulunmuştur. Kalite performansı alanında faklı kalite performans ölçütleri kullanılarak yapılmış başka çalışmalar da bulunmaktadır. Ancak Ahire vd. (1996)'nin kullandığı bu ölçütler diğer çalışmalarda kullanılan ölçütlere göre daha yüksek Cronbach's alpha'ya $(0,92)$ sahip olduğu için daha güvenli ve geçerlidir (Prajogo ve Sohal, 2006). Kaynak (1997), kalite performansı ölçütlerini; ürün/hizmet kalitesi, verimlilik, ıskarta ve yeniden işleme maliyeti, satın alınan malzemelerin 
teslimatı için teslim süresi, biten ürünlerin/hizmetin müşteriye teslimi için teslim süresi olarak belirlemiştir. Corbett ve Rastrick (2000) ise, kalite performansı ölçütlerini; tedarikçiden gelen kusurlu malzeme yüzdesi, ürün hacmindeki toplam hata yüzdesi, toplam satışlardan garanti talebi maliyeti, toplam satışlardaki kalite maliyeti (hata ıskarta, yeniden işleme, muayene) yüzdesi, direkt ürün operatörünün kalite kontrol muayene oranı, müşteriye tam zamanında teslim edilen teslimat oranı olarak belirlemişlerdir. Yapılan literatür araştırması sonucu çalışmada kullanılması için belirlenen kalite performans ölçütleri ve bu ölçütlerin kısaltmaları şöyledir: KP1: Ürünlerin performansı, KP2: Ürün / Hizmet Kalitesi. , KP3: Üretimdeki verimlilik, KP4: Biten ürünlerin / hizmetin müşteriye tam zamanında teslimat oranı, KP5: Ürünün güvenilirliliği, KP6: Ürünün dayanıklılı̆̆ı, KP7: Ürünün tasarım özelliklerine (spesifikasyonlara) uygunluğu, KP8: Ürünün standartlılı̆ı (ürün özelliklerinin üründen ürüne farklılık göstermemesi), KP9: Tedarikçiden gelen kusurlu malzeme yüzdesi, KP10: Toplam satışlardan garanti talebi maliyeti, KP11: Direkt ürün operatörünün kalite kontrol muayene oranı, KP12: Ürün hacmindeki toplam hata yüzdesi, KP13: Satın alınan malzemelerin teslimatı için teslim süresi, KP14: Iskarta ve yeniden işleme maliyeti.

\subsection{Teknoloji Transfer Performansı}

Çalışmamızda literatür araştırması ile Sung'un (2009), Lin vd. (2002)'nin, Souder vd. (1990)'nin, Mohamed vd. (2009)'nin, Trott vd. (1995)'nin, Guilfoos'un (1989), Wood ve EerNisse'nin (1992), Greiner ve Franza'nın (2003) çalışmalarından derlenen 50 teknolojik transfer performans faktörü ve bizim tarafımızdan belirlenen 9 teknoloji transfer başarı faktörü olmak üzere toplam 59 adet teknoloji transfer başarı faktörü kullanılmıştır. Bu 59 ölçüt için faktör analizi yapılarak 11 faktör elde edilmiştir. Çalışmada teknoloji transfer performansının belirlenmesi için kullanılan bu 11 ölçüt ve bu ölçütlerin çalışmada kullanılan kısaltmaları şöyledir: TP1: Yeterli ARGE'ye sahip olmak, TP2: Teknoloji transferi için çaba gösterilmesi, bilginin dağıtılması ve iletişim, TP3: Firma özelliklerine ve firma ihtiyaçlarına uygun, fayda sağlayacak teknolojinin transferi, TP4: Yeni teknolojiye adaptasyon ve yeni teknolojiyi uygulama kabiliyeti, TP5: Teknoloji transferinde kullanıcıya gerekli önemin verilmesi ve transfer konusunda başka organizasyonlar ile etkileşimde bulunulması, TP6: Teknoloji transferi için yeterli desteğin alınması, TP7: Teknoloji transferi konusunda çalışanların istekli olması ve ihtiyaçlara uygun seçilen teknolojinin çevre özelliklerine uygun hale getirilmesi, TP8: Teknoloji transferi için yeterli iletişimin olması, TP9: Yönetim odaklı organizasyon ve teknoloji kullanıcılarına yardım, TP10: Teknoloji transferi için devlet yardımı almak ve transfer edilen teknolojinin kullanılması, TP11: Destek, etkileşim ve transfer edilen teknoloji ile şirketin güçlenmesi.

\subsection{Kalite Performansı ve Teknoloji Transferi}

Vonderembse vd. (1995)'e göre ürünün kalitesi ürünün maliyetinden daha önemlidir. Kalite ürünün tercih edilmesinde en önemli unsur olduğu için kalite performansının nasıl arttırılacağı konusunda çeşitli çalışmalar yapılmıştır. Kalite performansının arttırılması sürekli iyileştirme, takım çalışması, müşteri odaklıık ile gerçekleşmektedir (Everett vd., 1997; Dean ve Bowen, 1994). Teknoloji transferi ile firmalar müşteri gereksinimlerini, isteklerini daha iyi ve daha hızıı karşılayabilmektedir. Müşteri memnuniyeti için çok önemli olan tam zamanında teslimatın yapılması, en iyi kalitede ürünün / hizmetin müşteriye sunulması teknoloji transferi ile mümkün olabilmektedir. Teknoloji transferinin sağladığı avantajlar sonucunda firma, kalite performansını arttırarak müşteri memnuniyetini sağlayabilmektedir. Ayrıca teknoloji transferi, firmanın iş süreçlerinde, üretiminde, sunduğu ürünlerde / hizmette sürekli iyileştirme ve gelişme içinde olmasına yardımcı olmaktadır. Teknoloji transferi firmalara her zaman bir yenilik sağlamaktadır. Yeni bir makine, yeni bir bilgisayar programı, yeni bir üretim yöntemi vb. her yeni teknoloji firmanın mevcut süreçlerini, ürünlerini / hizmetlerini, organizasyon yapısını daha iyi hale getirmesine, iyileştirmesine sebep olur. $\mathrm{Bu}$ durum kalite performansını arttıracak sürekli iyileştirme faktörünü sağlamaktadır.

Kalite performansını arttıran bir diğer faktör olan takım çalışması da teknoloji transferi ile sağlanmaktadır. Çünkü teknoloji transfer sürecinin başlangıcı olan teknolojinin seçim aşamasından, temin edilmesi, firmaya uyarlanması, çalışanlar tarafından öğrenilmesi, benimsenmesi ve gerekli değişikliklerin yapılarak yeniden üretilmesi aşamaları boyunca firmanın başarılı olabilmesi için her zaman firmadaki tüm bölümlerden oluşan bir takım ile çalışılması gereklidir. Takım çalışmasının yapılmadığı, firmadaki tüm çalışanların fikirlerinin dikkate alınmadığı, transfer sürecine çalışanların dahil edilmediği firmalarda teknoloji transferi başarısızlık ile sonuçlanmıştır. Bu konuda literatürde yazıımış birçok araştırma bulunmaktadır. Teknoloji transferi için bir takım çalışmasının gerekmesi, çalışanların bir takım halinde hareket etmesi de teknoloji 
transferi gerçekleştirecek firmanın kalite performansını arttırmasını sağlar. Çünkü kalite performansının artması için takım çalışması çok önemli bir faktördür.

Teknoloji transferinin kalite performansına etkisinin araştırılması sonucu bulunacak olumlu sonuçlar firmaları teknoloji transferi yapma konusunda teşvik edecektir. Ülkemizde firmaların gerçekleştirdiği teknoloji transferi sayısı arttıkça firmalar; rekabet ortamında müşterilerine, müşteri beklentilerini, ihtiyaçlarını karşılayabilen daha iyi ve daha yeni ürünler / hizmetler sunabilecektir. Dolayısıyla firmaların performanslarının teknoloji transferinden sonra artacağı beklenmektedir. Transfer edilen yeni teknoloji ile firmalar daha hızlı iş süreçlerine sahip olmakta ve insan faktörünü arka plana atan sistemlere sahip olmaktadır. Bu durum firmalarda kalite performansının yeni teknolojiden olumsuz yönde etkilenmesi ile ilgili kaygı ve endişelere sebep olmaktadır. Bu araştırma firmalara bu açıdan yardımcı olacaktır.

Tablo 1 : Örneklemdeki firmaların özellikleri.

\begin{tabular}{|lr|}
\hline Sektörler & Yüzde (\%) \\
\hline Gıda & 15.5 \\
Tekstil & 15 \\
Metal sanayi & 12.5 \\
Otomotiv & 11 \\
İnşaat & 7 \\
Makine ve teçhizat & 6.5 \\
Kağıt, kağıt ürünleri, basım sanayi & 6 \\
Enerji & 5 \\
Kimya & 3.5 \\
Plastik & 3 \\
Taş ve toprağa dayalı sanayi & 2.5 \\
Orman ürünleri ve mobilya & 2.5 \\
İlaç & 2.5 \\
Maden ve madeni eşya & 2 \\
Elektronik & 1.5 \\
Temizlik & 1 \\
Tütün & 1 \\
Ziraat Kimyasalları & 1 \\
Cam & 0.5 \\
Havacıllk & 1 \\
& \\
\hline
\end{tabular}

\section{TEKNOLOJI TRANSFERININ KALITE PERFORMANSINA ETKISININ ARAŞTIRILMASI}

Çalışmanın araştırma sorusu, "teknoloji transferinin kalite performansını etkileyip etkilemediği, etkiliyor ise pozitif veya negatif olarak hangi yönde etkilediğidir". Araştırmada Türkiye'deki üretim sektöründe faaliyet gösteren Sanayi Odası'nın 2012 yılı için belirlediği ilk 1000 firma içinde yer alan 200 firmaya yüz yüze anket yapılmıştır. Araştırmaya dahil edilen firmalar rassal olarak seçilmiştir. Tablo 1'de araştırmaya katılan firmaların özelliklerine ait bulgular görülmektedir. Tablo 1'de görüldüğü gibi araştırmamıza katılan firmalar 20 farklı sektörde faaliyet göstermektedir. Çalışmadaki firmaların en çok faaliyette bulundukları sektörler; gıda, tekstil, metal sanayi ve otomotivdir.

\begin{tabular}{|lr|}
\hline Faaliyet Yılı & Yüzde (\%) \\
\hline $0-6$ yıl & 2 \\
$7-16$ yıl & 13 \\
$17-26$ yıl & 18.5 \\
$27-36$ yıl & 24 \\
37 yıl ve üzeri & 42.5 \\
\hline Çalışan Sayısı & Yüzde (\%) \\
\hline$=<50$ & 1,5 \\
$51-100$ & 3 \\
$101-150$ & 6 \\
151 - 200 & 3.5 \\
$201-250$ & 5 \\
$251>=$ & 81 \\
\hline Scale of Firm & Yüzde (\%) \\
\hline Büyük Ölçekli Firma & 81 \\
Küçük Ölçekli Firma & 19 \\
\hline Sermaye Yapısı & Yüzde (\%) \\
\hline \% 100 Yerli & 81 \\
$\% 100$ Yabancı & 6 \\
Yerli - Yabancı Ortak & 13 \\
\hline
\end{tabular}


Sağladığı avantajlardan dolayı günümüzde tercih edilen bir yöntem olan yapısal eşitlik modellemesi (Structural Equation Model - SEM) araştırma modelinin analizi için kullanılmışıtr. Yapısal eşitlik modellemesi yöntemi için örnek hacminin olması gereken büyüklüğü çeşitli araştırmacılar tarafından 200-500 aralığında ifade edildiğinden (Kline, 1998; Möbius, 2003; Dursun ve Kocagöz, 2010), söz konusu örnek hacmi yeterli bulunmuştur. Araştırmada kullanılacak soruları kalite bölümü veya imalat bölümü yöneticileri cevaplamıştır. Çok çeşitli teknoloji transfer türleri bulunmaktadır. Belirli teknoloji transfer türlerini gerçekleştirmiş firmaları araştırmaya dahil etmek yerine teknoloji transfer türlerinden herhangi birini gerçekleştirmiş tüm üretim firmaları araştırmaya dahil edilmiştir. Böylece araştırmanın daha kapsamlı olması sağlanmıştır.

\subsection{Araştırma Modeli}

Araştırmanın amacı dikkate alınarak araştırma modeli Şekil 1'deki gibi oluşturulmuştur.

\begin{tabular}{|l|l|l|}
\hline $\begin{array}{l}\text { TEKNOLOJI } \\
\text { TRANSFER } \\
\text { PERFORMANSI }\end{array}$ & $\longrightarrow \begin{array}{l}\text { KALITE } \\
\text { PERFORMANSI }\end{array}$ \\
\hline
\end{tabular}

Şekil 1: Araştırma Modeli

\subsection{Hipotezler}

Araştırma modeline dayanarak oluşturulan çalışmanın hipotezleri şöyledir:

$\mathbf{H}_{1}$ : Firmanın teknoloji transfer performansının yüksek olması firmanın kalite performansını pozitif yönde etkiler.

$\mathbf{H}_{2}$ : Teknoloji transfer performansının farklı kalite performans ölçütlerine etkisi arasında fark vardır.

\section{BULGULAR}

Araştırma sonucu elde edilen veriler IBM SPSS Statistics 17.0 ve IBM SPSS Amosv20 programları kullanılarak analiz edilmiştir. Yapılan güvenilirlik analizi sonucunda teknoloji transfer performansı değişkeninin Cronbach's Alpha değeri 0,972, kalite performansı değişkeninin Cronbach's Alpha değeri ise 0,895 bulunmuştur. Tüm değişkenler tüm ifadeleri ile birlikte analiz edildiğinde 0,70'in üstünde bir Cronbach's Alpha değerine sahip oldukları için güvenilirdiler.

\subsection{Yapısal Eşitlik Modeli ile Araştırma Modelinin Test Edilmesi}

Araştırmanın modelindeki değişkenlere ait yapısal model ve ölçüm modelinin yer aldığı yol diyagramları Şekil 2'de gösterilmiştir.

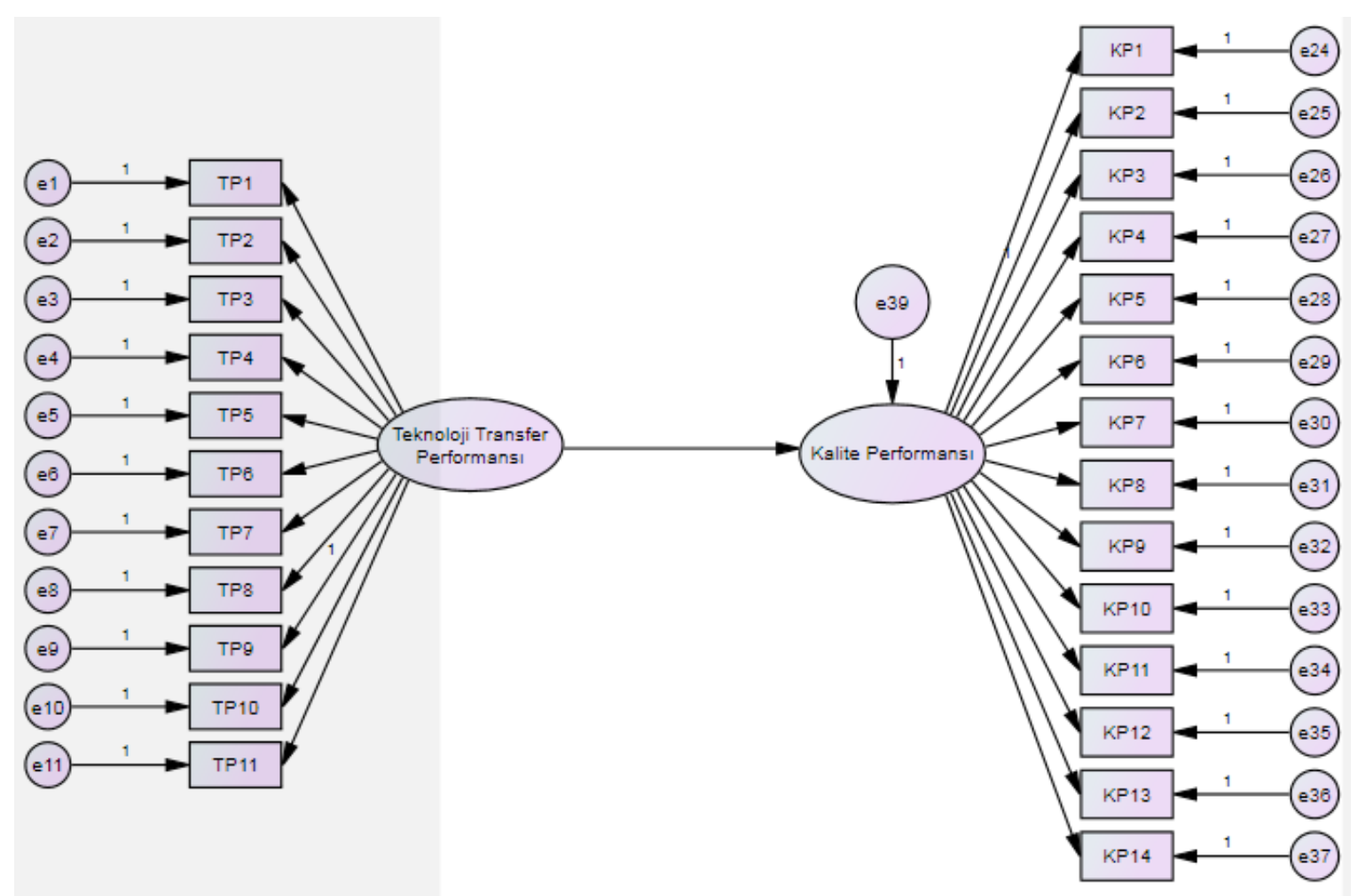

Şekil 2: Yapısal model ve ölçüm modelinin yer aldığı yol diyagramı 


\subsection{Modelin İstatistiksel Uygunluğu}

Model uygunluğunun değerlendirilmesinde kullanılan birbirinden farklı uyum iyiliği indeksleri ve bu indekslerin sahip olduğu istatistiksel fonksiyonlar vardır.

Bunlar üç grupta toplanabilir:

- Ki-kare $\left(X^{2}\right)$ uyum iyiliği testi (Chi-Square Goodness of Fit),

- Uyum iyiliği indeksi (Goodness of Fit Index),

- Karşılaştırmalı uyum indeksi (Comperative Fit Indices).

Model uyumluluğunu gösteren uyum iyiliği indeksleri için iyi uyum ve kabul edilebilir uyum sınırları Tablo 2'de verilmiştir.

Çalışmanın modelinin uygunluğunun testi sonucunda elde edilen uyum ölçütleri değerleri Tablo 3'de görülmektedir. Tablo 3'de görüldüğü gibi çalışmamızın ölçüm modelleri analiz edildiğinde uyum iyiliği ölçütlerinin çoğu için kabul edilebilecek bir değer almamıştır.

\subsection{Modelin modifikasyonu}

Çalışmadaki modellere ilişkin uyum ölçütleri bütünsel olarak değerlendirildiğinde, modellerin düzeltme indeksleri ve değişkenler arasındaki ilişkiler yeniden gözden geçirilerek, modellerin düzeltilmesi gerektiği görülmektedir. Modelin daha iyi bir uyuma sahip olması için analiz sonucunda elde edilen düzeltme indeksleri modele en çok katkı sağlayacak olandan başlayarak önerilen modifikasyonlar araştırmanın teorik çerçevesi temelinde yorumlanarak modele eklenir. Böylece model yeniden tanımlanır ve tekrar analiz edilir. Modelin yapılan modifikasyonlar sonucundaki son hali ve standartlaştırımış katsayıları Şekil 3'de görülmektedir. Standartlaştırılmış yükler, her bir gözlenen değişken ile ilgili olduğu gizil değişken arasındaki korelasyonları göstermektedir (Yılmaz ve Çelik, 2009).

Tablo 2: Doğrulayıcı faktör analizi için öngörülen uyum iyiliği değerleri (Schermelleh-Engel ve Moosbrugger, 2003).

\begin{tabular}{lll}
\hline Uyum Ölçüleri & lyi Uyum & Kabul Edilebilir Uyum \\
\hline RMSEA & $0<\mathrm{REMSEA}<0.05$ & $0.05 \leq \mathrm{RMSEA} \leq 0.10$ \\
$\mathrm{NFI}$ & $0.95 \leq \mathrm{NFI} \leq 1$ & $0.90 \leq \mathrm{NFI} \leq 0.95$ \\
$\mathrm{CFI}$ & $0.97 \leq \mathrm{CFI} \leq 1$ & $0.95 \leq \mathrm{CFI} \leq 0.97$ \\
$\mathrm{GFI}$ & $0.95 \leq \mathrm{GFI} \leq 1$ & $0.90 \leq \mathrm{GFI} \leq 0.95$ \\
$\mathrm{AGFI}$ & $0.90 \leq \mathrm{AGFI} \leq 1$ & $0.85 \leq \mathrm{AGFI} \leq 0.90$ \\
$\mathrm{IFI}$ & $0.97 \leq \mathrm{IFI} \leq 1$ & $0.95 \leq \mathrm{IFI} \leq 0.97$ \\
$\mathrm{RFI}$ & $0.90 \leq \mathrm{RFI} \leq 1$ & $0.85 \leq \mathrm{RFI} \leq 0.90$ \\
$\mathrm{X}^{2} / \mathrm{df}$ & $0<\mathrm{X}^{2} / \mathrm{df}<2$ & $2<\mathrm{X}^{2} / \mathrm{df}<5$ \\
\hline
\end{tabular}

Tablo 3: Doğrulayıcı faktör analizi uyum iyiliği değerleri

\begin{tabular}{lll}
\hline Uyum Ölçüleri & Değer & Sonuç \\
\hline X2 & 724,721 & \\
$\mathrm{df}$ & 274 & \\
$\mathrm{X} 2 / \mathrm{df}$ & 2,645 & Kabul edilebilir \\
$\mathrm{p}$ & 0,000 & \\
$\mathrm{RMSEA}$ & 0,091 & Kabul edilebilir \\
$\mathrm{NFI}$ & 0,777 & Kabul edilemez \\
$\mathrm{CFI}$ & 0,847 & Kabul edilemez \\
$\mathrm{GFI}$ & 0,732 & Kabul edilemez \\
$\mathrm{AGFI}$ & 0,682 & Kabul edilemez \\
$\mathrm{IFI}$ & 0,848 & Kabul edilemez \\
RFI & 0,756 & Kabul edilemez \\
\hline
\end{tabular}


Çalışmanın birinci modeli için gözlenen değişkenlerin hata terimleri arasındaki önerilen ilişkiler gerçekleştirildiğinde modelin yeterli uyum ölçütlerine sahip olduğu görülmüştür. Bu sebeple modelde başka bir değişiklik yapılmasına gerek kalmamıştır. Bir ölçme modelinde gözlenen değişkenlerin hatalarının birbirleriyle ilişkili olması bu değişkenlerin birbirleriyle diğer değişkenlere oranla daha yakından ilişkili olduklarına ve bu ilişkinin aslında başka bir gizil değişkenin gözlenen değişkeni olarak tanımlanabilme olasılığından kaynaklanabileceğine işaret eder. Gözlenen değişkenlerin hataları arasında bulunan yüksek orandaki ilişki, bu değişkenlerde açıklanmayan varyansın aslında modelde öngörülemeyen bir başka gizil değişken tarafından açıklanabilir olduğuna ilişkin gösterge niteliğindedir (Şimşek, 2007; Hair vd., 1998).

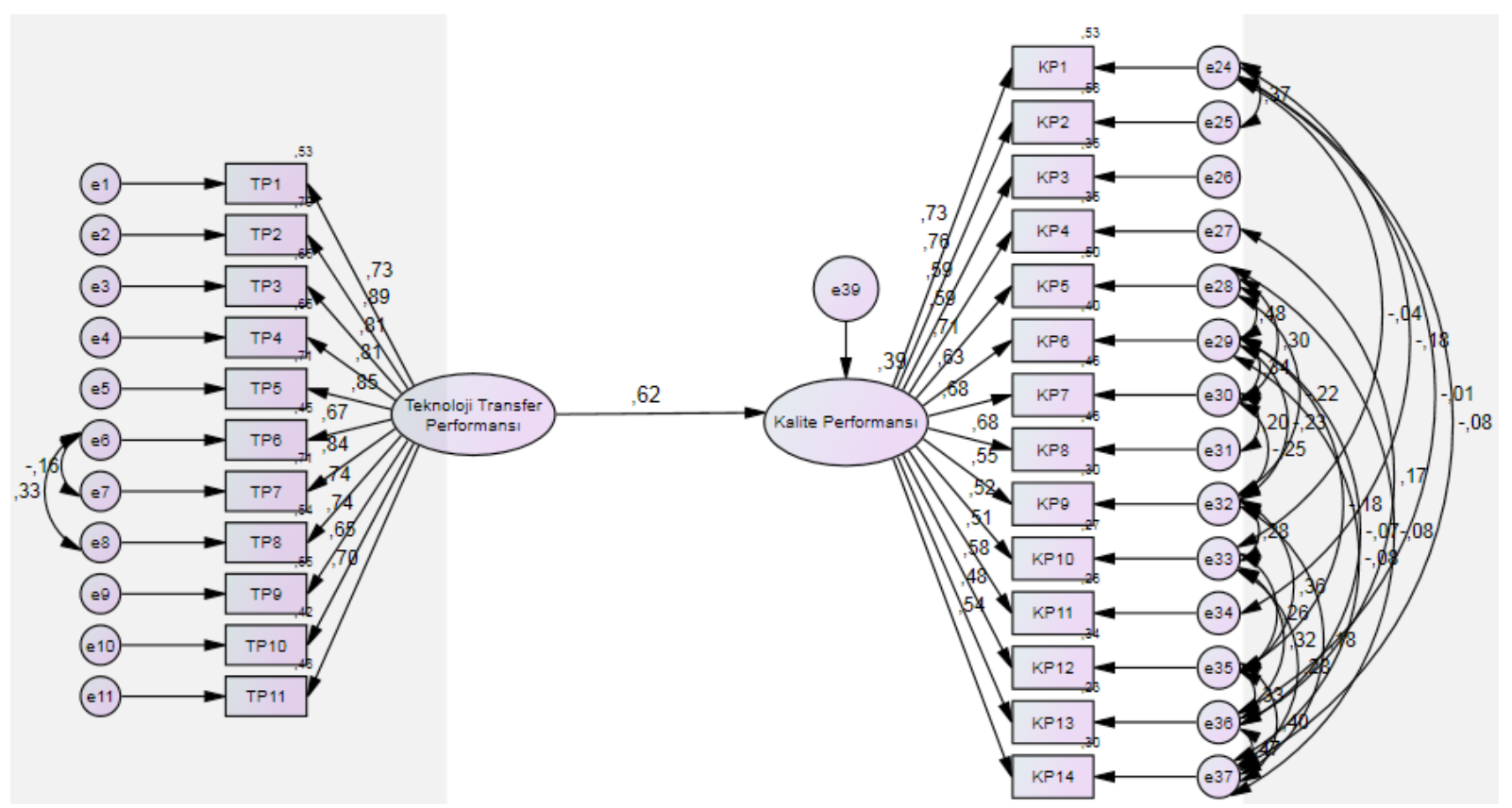

Şekil 3: Modelin modifikasyon sonucundaki son hali ve standartlaştııılmış katsayılar

Tablo 4: Modifikasyon sonrası birinci model için doğrulayıcı faktör analizi uyum iyiliği değerleri

\begin{tabular}{lll}
\hline Uyum Ölçütleri & Değer & Sonuç \\
\hline$X^{2}$ & 344,433 & \\
$\mathrm{df}$ & 246 & \\
$\mathrm{X}^{2} / \mathrm{df}$ & 1,400 & İyi Uyum \\
$\mathrm{p}$ & 0,000 & \\
$\mathrm{RMSEA}$ & 0,045 & İy Uyum \\
$\mathrm{NFI}$ & 0,894 & Kabul edilebilir \\
CFI & 0,967 & Kabul edilebilir \\
GFI & 0,882 & Kabul edilebilir \\
AGFI & 0,844 & Kabul edilebilir \\
IFI & 0,967 & Iyi Uyum \\
RFI & 0,871 & Kabul edilebilir \\
\hline
\end{tabular}


Düzeltilmiş modele ait uyum ölçütleri Tablo 4'de görülmektedir. NFI, GFI değerleri için kabul edilebilir alt sınır değeri 0,90 ve AGFI değeri için de kabul edilebilir alt sınır $0,85^{\prime}$ dir. Çalışmada modifikasyon sonucu birinci model için elde edilen NFI değeri 0,894, GFI değeri de 0,882 'dir. Bu değerler, 0,90'a çok yakın değerler olduğu için düzeltilmiş birinci model için NFI ve GFI değerleri kabul edilebilir uyuma sahip olarak değerlendirilmiştir. IFI değeri de 0,967 olup yaklaşık olarak 0,97 kabul edilerek model IFI açısından iyi uyuma sahip olarak değerlendirilmiştir. Tablo 5'deki ölçüm modeli sonuçlarında, modeldeki değişkenlerin standartlaştırılmış faktör yükleri, faktör yükleri için hesaplanan $\mathrm{t}$ değerleri ve faktör yüklerinin karesi alınarak elde edilen $R^{2}$ değerlerinin görülmektedir. Uyum ölçütleri bir bütün olarak çalışmanın modelinin kabul edilebilirliğini göstermektedir. Ancak modelin genel kabulü, modelde yer alan tüm içsel ilişkilerin anlamlı olduğunu göstermemektedir.

Her gizil faktörün uygunluğu ayrı ayrı değerlendirildiğinde; ilk olarak gizil değişkenler altında tanımlanan gözlenen değişkenlerin faktör yüklerinin istatistiksel olarak anlamlı olması gerekmektedir. İkinci olarak gizil faktörlerin güvenirliğinin ve açıklanan varyansın değerlendirilmesi gerekmektedir. Her bir gözlenen değişkenin, faktör yükü için hesaplanan $t$ değeri, kritik $t$ değerinden büyük ise faktör yükünün istatistiksel olarak anlamlı olduğuna karar verilir. 0,05 anlam düzeyinde kritik $t$ değeri 1,96; 0,01 anlam düzeyinde ise kritik t değeri 2,576'dır (Yılmaz ve Çelik, 2009).

Tablo 5: Ölçüm modeli sonuçları

\begin{tabular}{|c|c|c|c|c|}
\hline Faktör & & Standartlaştırılmış Yükler & t-değeri & $\mathbf{R}^{2}$ \\
\hline \multirow{11}{*}{$\begin{array}{l}\text { Teknoloji Transfer } \\
\text { Performansı }\end{array}$} & TP1 & 0,729 & 10,557 & 0,531 \\
\hline & TP2 & 0,890 & 13,232 & 0,792 \\
\hline & TP3 & 0,809 & 11,863 & 0,654 \\
\hline & TP4 & 0,810 & 11,886 & 0,656 \\
\hline & TP5 & 0,845 & 12,475 & 0,714 \\
\hline & TP6 & 0,673 & 9,625 & 0,452 \\
\hline & TP7 & 0,842 & 12,411 & 0,709 \\
\hline & TP8 & 0,736 & 10,660 & 0,541 \\
\hline & TP9 & 0,745 & & 0,555 \\
\hline & TP10 & 0,646 & 9,242 & 0,417 \\
\hline & TP11 & 0,695 & 10,017 & 0,483 \\
\hline \multirow{14}{*}{ Kalite Performansı } & KP1 & 0,731 & 12,897 & 0,535 \\
\hline & KP2 & 0,762 & & 0,580 \\
\hline & KP3 & 0,593 & 8,130 & 0,352 \\
\hline & KP4 & 0,593 & 8,127 & 0,351 \\
\hline & KP5 & 0,706 & 9,659 & 0,499 \\
\hline & KP6 & 0,634 & 8,544 & 0,402 \\
\hline & KP7 & 0,682 & 9,254 & 0,465 \\
\hline & KP8 & 0,678 & 9,350 & 0,459 \\
\hline & KP9 & 0,551 & 7,349 & 0,304 \\
\hline & KP10 & 0,524 & 7,027 & 0,274 \\
\hline & KP11 & 0,512 & 6,925 & 0,262 \\
\hline & KP12 & 0,584 & 7,931 & 0,341 \\
\hline & KP13 & 0,483 & 6,486 & 0,233 \\
\hline & KP14 & 0,543 & 7,258 & 0,295 \\
\hline $\begin{array}{l}\text { Teknoloji Transferi } \\
\text { Performansı }\end{array}$ & Kalite Performansı & 0,621 & 7,407 & 0,378 \\
\hline
\end{tabular}


TP9 ve KP2 için standartlaştırılmamış faktör yükleri 1 olduğu için analiz sonucu bu değişkenlerin t değeri bulunmamaktadır.0,05 anlam düzeyinde birinci modele ait tüm değişkenlerin faktör yükü t değerleri 1,96'dan büyük olduğu için faktör yükleri istatistiksel olarak anlamlıdır.

Birinci model için teknoloji performansı faktörüne ilişkin değişkenliğin en çok TP2 değişkeni tarafından açıklandığı görülmektedir $\left(R^{2}=0,792\right)$. Dolayısıyla teknoloji transferi için çaba gösterilmesi, bilginin dağıtılması ve iletişime (TP2) ait varyansın \% 79,2'sinin ilgili değişkenlerce açıklanabildiği söylenebilir. Ayrıca kalite performansı faktörüne ilişkin değişkenliğin de en çok KP2 değişkeni tarafından açıklandığı görülmektedir $\left(R^{2}=0,580\right)$. Ürün / hizmet kalitesine (KP2) ait varyansın \% 58'i ilgili değişkenlerce açıklanabilmektedir.

Standardize katsayılar, bağımsız değişkende gerçekleştirilecek bir standart sapmalık değişimin bağımlı değişkende yaratması beklenen artışı ifade etmektedir. Örneğin Tablo 5 dikkate alındığında, yeterli ARGE'ye sahip olma (TP1) ile ilgili olarak gerçekleştirilecek olan bir standart sapmalık değişimin, teknoloji transfer performansı üzerinde 0,729 standart sapma düzeyinde bir değişiklik yaratması beklenmektedir. Bu sebeple, standart regresyon katsayıları aynı zamanda sunulan modelde yer alan her bir değişkenin göreli önemi anlamına da gelmektedir. Teknoloji transfer performansını en iyi tahmin eden bağımsız değişkenin teknoloji transferi için çaba gösterilmesi, bilginin dağıtılması ve iletişim (TP2) değişkeni olduğu görülür. Çünkü TP2, Tablo 5'de de görüldüğü gibi en yüksek standardize edilmiş yol katsayısına sahip bağımsız değişkendir.

\section{4 Ölçme modelinin değerlendirilmesi}

Ölçme modelinin değerlendirilmesi için her bir faktör yükü incelenmeli ve her bir faktöre ait birleşik güvenirlik ve açıklayıcı varyans hesaplanmalıdır. Ölçek güvenirliği için güvenirlik ölçümüne ilişkin tahminlerin 0,70'in üstünde olması gerekmektedir. Açıklayıcı varyans, örtük değişkeni oluşturan tüm gösterge değişkenlerdeki varyansların toplamıdır. Açıklanan varyans ölçümüne ilişkin tahminin 0,50'nin üstünde olması gerekmektedir (Hair vd., 1998).

Birleşik Güvenirlik = (Standartlaştırılmış yükler toplamı $)^{2}$ / [(Standartlaştırılmış yükler toplamı $)^{2}+$ (Gözlenen değişkenlerin ölçüm hataları toplamı)]
Açıklayıcı Varyans = (Standartlaştırılmış yüklerin kareleri toplamı) / [(Standartlaştırılmış yüklerin kareleri toplamı) + (Gözlenen değişkenlerin ölçüm hataları toplamı)]

Kalite performansı için birleşik güvenirlik değeri 0,894 ve açıklayıcı varyans değeri 0,382'dir. Teknoloji transfer performansı faktörleri için ise birleşik güvenirlik değeri 0,940 ve açıklayıcı varyans değeri 0,591'dir. Modeldeki faktörlerin birleşik güvenirlik değerleri 0,7'den büyük değerlerdir. Böylece birinci modelin ölçek güvenirliği bulunmaktadır. Açıklayıcı varyans değerleri de 0,50 ve üstündedir. Dolayısıyla gösterge değişkenleri, örtük değişkenleri doğru bir şekilde açıklamaktadır diyebiliriz.

$\mathbf{H}_{\mathbf{1}}$ : Firmanın teknoloji transfer performansının yüksek olması firmanın kalite performansını pozitif yönde etkiler.

Yapısal eşitlik modellemesi sonucunda $\mathrm{H}_{1}$ kabul edilmiştir. Çünkü teknoloji transfer performansı ile kalite yönetimi arasında pozitif yönde bir ilişki olduğu yol katsayısı $(0,621)$ incelendiğinde görülmektedir. Ayrıca 0,05 anlamlılık düzeyinde bu ilişkinin anlamlı olduğu görülmektedir. Sonuç olarak firmanın teknoloji transfer performansının yüksek olması firmanın kalite performansını pozitif yönde etkilemektedir.

$\mathbf{H}_{\mathbf{2}}$ : Teknoloji transfer performansının farklı kalite performans ölçütlerine etkisi arasında fark vardır.

$\mathrm{H}_{2}$ hipotezinin testi için tek yönlü MANOVA testi yapılmıştır. Tablo 6'da tek yönlü MANOVA testi sonuçları görülmektedir. Tablo 6'da görüldüğü gibi Wilk's Lambda satırındaki Sig. değeri 0,846, olduğu ve 0,05 değerinden büyük bir değer olduğu için $\mathrm{H}_{2}$ reddedilir. Yani teknoloji transfer performansının farklı kalite performans ölçütlerine etkisi arasında fark yoktur sonucu bulunur.

Tablo 6: $\mathrm{H}_{2}$ için MANOVA test sonuçları

\begin{tabular}{lccc}
\hline Etki & Wilks' Lambda & $F$ & Sig. \\
\hline $\begin{array}{l}\text { Teknoloji } \\
\text { Transfer }\end{array}$ & ,000 &, 946 &, 846 \\
Performansı & & & \\
\hline
\end{tabular}

\section{SONUÇLAR}

Günümüz rekabet koşullarında firmalar müşterilerini memnun edebilmek için ürün ve hizmetlerinin kalitesine gereken önemi vermek, kalite performans- 
larını sürekli arttırmak zorundadırlar. Literatür araştırması sonucunda teknoloji transfer performansının kalite performansına etkisini gösteren bir çalışmaya rastlanmamıştır ve bu eksikliğin giderilmesi amacıyla çalışmamızda bir model geliştirilmiştir. Bu model yapısal eşitlik modellemesi kullanılarak analiz edilmiştir. Araştırma sonucunda teknoloji transferinin kalite performansına pozitif yönde bir etkisi olduğu sonucu bulunmuştur. Çalışmamızda teknoloji transfer performansının farklı kalite performans ölçütlerine etkisi arasında fark olmadığı sonucu da bulunmuştur. Elde edilen bu sonucun firmaların yüksek kalite performansı sağlamak için teknoloji transferi yapmalarını teşvik edeceği beklenmektedir. Çalışmamızda litera- türde yer alan teknoloji transfer performans faktörleri araştırılıp derlenmesi ile teknoloji transfer performansını ölçebilmek için bir ölçek geliştirilmiştir. Bu ölçeğin teknoloji transferi konusundaki literature katkı sağlayacağı düşünülmektedir. Yapılan literatür çalışması ile çok sayıda araştırma incelenerek kalite performans ölçütleri belirlenmiştir, Bu ölçütler derlenerek yapılan anket çalışması ile güncel ölçütler oluşturulmuştur. Türkiye'de yapılan alan araştırması ile teknoloji transferinin kalite performansını pozitif yönde etkilediği bulunmuştur. Bu bulgunun Türkiye'deki firmaların teknoloji transfer süreçlerine ve kalite performanslarına katkı sağlayacağı düşünülmektedir.

\section{KAYNAKLAR}

Ahire S.L., Golhar D.Y. ve Waller M.W. (1996) "Development and validation of TQM implementation constructs" Decision Sciences, 27 (1), 23-56.

Betts, S.C. ve M.D. Santoro (2009) "Controlling IndustryUniversity Relationships for Initial and Continuing Success", Proceedings of the Academy of Strategic Management, Allied Academies International Conference, New Orleans, 8(1), 12- 17.

Corbett, L.M. ve Rastrick, K.N. (2000) "Quality Performance and Organizational Culture A New Zealand Study" International Journal of Quality \& Reliability Management, MCB University Press, 17- (1), 14-26.

Dean, J.W. ve Bowen, D.E. (1994) "Management theory and total quality: Improving research and practice through theory development" The Academy of Management Journal, 19 (3), 392-418.

Dursun, Y. ve Kocagöz E. (2010) "Yapisal Eşitlik Modellemesi Ve Regresyon: Karşilaştirmali Bir Analiz" Erciyes Üniversitesi İktisadi ve İdari Bilimler Fakültesi Dergisi, Sayı: 35, Ocak-Temmuz 2010 1-17.

Everett E. A. J., Lawrence, M.C. ve Flores B.E. (1997) “An International Study of Quality Improvement Approach and Firm Performance" International Journal of Operations \& Production Management, MCB University Press, 17 (9), 842-873.

Greiner M,. A. ve Franza, R., M. (2003) "Barriers and Bridges for Successful Environmental Technology Transfer" Journal of Technology Transfer, 28, 167-177.

Guilfoos, S.J. (1989) “Bashing the Technology Insertion Barriers" Air Force Journal of Logistics, Cilt 13 (1), 27-32.
Hair, J. F., Anderson, R. E., Tatham, R. L. ve Black, W. C. (1998) "Patterns of Multivariate Data Analysis" Prentice Hall, 4th ed., Upper Saddle River.

Jöreskog, K.G. ve Sörbom, D. (1993) "Lisrel 8: Structural equation modeling with the SIMPLES comman language" Lincolnwood, IL: Scientific Software International.

Kaynak, H. (1997) "Total Quality Management and Justin-Time Purchasing: Their Effects on Performance of Firms Operating in the US" Garland, New York, NY.

Kline, Rex B. (1998) Principles and Practice of Structural Equation Modeling, NY: Guilford Press, 354.

Lin, C., Tan, B. ve Chang, S. (2002) "The critical factors fortechnology absorptive capacity" Industrial Management \& Data Systems, 102 (6), 300-308.

Mobius, M. (2003) "The Use of Item Parcelling in Statistical AnalysesA Research Example", 2nd. European Conference on Research Methodology for Business and Management, ss. 247-256.

Mohamed, A.S., Sapuan, S.M., Megat Ahmad, M.M.H, Hamouda, A.M.S. , Hang Tuah Bin ve Baharudin B.T. (2009) "The Effect of Technology Transfer Factors on Performance: An Empirical Study of Libyan Petroleum Industry" American Journal of Applied Sciences, 6 (9), 1763-1769.

Prajogo, D.I. ve Sohal A.S. (2006) "The integration of TQM and technology/R\&D management in determining quality and innovation performance" The International Journal of Management Science, Omega 34, 296-312.

Sazali A.W., Raduan C.R., Suzana I., Wati O. (2012) "Defining the Concepts of Technology and Technology 
Transfer: A Literature Analysis", International Business Research, 5(1), 63.

Schermelleh-Engel, K. ve Moosbrugger, H. (2003) "Evaluating the fit of StructuralEquation Models: tests of significance and descriptive goodness of fit measures" Methods of Psychological Research Online, 8 (2), 23-74.

Souder, W.E., Nasher, A.S. ve Padmanabhan, V. (1990) "A Guide to the Best Technology Transfer Practices" Journal of Technology Transfer, 15 (1): 2, 5-16.

Sung, T.K. (2009) "Technology transfer in the IT industry: A Korean perspective" Technological Forecasting \& Social Change, 76, 700-708.

Şimsek, Ö. F. (2007) Yapısal Eşitlik Modellemesine Giriş: Temel Illkeler ve LISREL Uygulamaları, Ekinoks Yayınevi, Ankara.
Trott, P., Cordey-Hayes, M. Ve Seaton, R.A.F. (1995) "Inward Technology Transfer as an Interactive Process" Technovation, 15 (1), 25-43.

Vonderembse, M.A., Tracey, M., Tan, C.L. ve Bardi, E.J. (1995) "Current purchasing practices and JIT: some of the effects on inbound logistics" International Journal of Physical Distribution and Logistics Management, 25 (3), 33-48.

Wood, O.L. ve EerNisse, E.P. (1992) “Technology Transfer to the Private Sector from a Federal Laboratory" IEEE Engineering Management Review, 20 (1), 23-28.

Yılmaz, V. ve Çelik H.E. (2009) Lisrel ile Yapısal Eşitlik Modellemesi - I: Temel Kavramlar, Uygulamalar, Programlama, Pegem Akademi Yayınevi, Ankara. 
